\title{
IN SEARCH OF BEST PRESSURE FLOW CRITERIA TO DEFINE BLADDER OUTLET OBSTRUCTION IN INDIAN FEMALES
}

\author{
Prasenjit Majee ${ }^{1}$, Ranjit Kumar Das², Arpan Chowdhury33, Ranjan Kumar Dey4, Vishnu Agarwal ${ }^{5}$ \\ ${ }^{1}$ Senior Resident, Department of Urology, RG Kar Medical College, Kolkata. \\ 2 Professor \& HOD, Department of Urology, RG Kar Medical College, Kolkata. \\ ${ }^{3}$ Senior Resident, Department of Urology, RG Kar Medical College, Kolkata. \\ ${ }^{4}$ Associate Professor, Department of Urology, RG Kar Medical College, Kolkata. \\ ${ }^{5}$ Senior Resident, Department of Urology, RG Kar Medical College, Kolkata.
}

\section{ABSTRACT}

\section{BACKGROUND}

Bladder outlet obstruction in females is increasingly being understood. However, caveats remain in defining clinical and urodynamic parameters to suggest BOO precisely. We compared urodynamic parameters of women with obstructive voiding to control, to better characterise BOO.

\section{MATERIALS AND METHODS}

Prospective observational study included 80 females with LUTS and 20 others, admitted for nephrolithiasis without LUTS, as control. Patients were divided into three groups based on symptomology. Group A had obstructive symptoms; Group B had irritative symptoms; while C was control. Clinical evaluation, Qmax, PVR, cystourethroscopy and urodynamic study were performed. ANOVA, Chi-square and ROC curve were used. Fixed combinations [set1 (Qmax $<12$, PdetQmax $>20)$, set2 $(\mathrm{Qmax}<15$, PdetQmax>30)] were tested to define BOO.

\section{RESULT}

Mean age in group $A(n=27), B(n=53)$ and $C(n=20)$ was $43 \pm 17,40 \pm 14$ and $37 \pm 12$ years respectively. Group A had lower Qmax

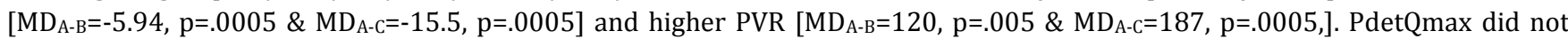
differ significantly $(p=.061)$. BOO was found in $16 / 27$ and $9 / 53$ cases in group A and B respectively [Pearson value=25.38, $\mathrm{p}=.0005]$. AUC for BOOI, Qmax, PdetQmax, PVR and MVV was 0.956, 0.939, 0.866, 0.810 and 0.809, respectively. Predicted cut-off values of above parameters were $4.7,13.15,28.5,68.5$ and 290.5 . Set1 had lower sensitivity than set2 (80\% v/s $84 \%)$, but higher specificity (94.5\% v/s 87.3\%).

\section{CONCLUSION}

We suggest Qmax<13.1 mL/s, PdetQmax> $=28.5 \mathrm{~cm} \mathrm{H} 2$, BOOI of $>=4.7$ and PVR of $>=68.5 \mathrm{~mL}$, as cut-off limit to define BOO. Relation with symptomology is modest. Fixed combination may give variable result; correlation with all parameters helps indeed.

\section{KEYWORDS}

Bladder Outlet Obstruction, Female Urology, Female Voiding Dysfunction, Urodynamic Study, Pressure Flow Study.

HOW TO CITE THIS ARTICLE: Majee P, Das RK, Chowdhury A, et al. In search of best pressure flow criteria to define bladder outlet obstruction in Indian females. J. Evolution Med. Dent. Sci. 2017;6(65):4686-4690, DOI: 10.14260/Jemds/2017/1014

\begin{abstract}
BACKGROUND
Bladder outlet obstruction (BOO) is a bothersome problem, with significant alteration in quality of life, ranging in all ages and both sexes. In females, specific concern arises in defining the B00 accurately. Clinical symptoms alone are poor predictors of BOO, as women present with diversity of mixed symptoms.[1] Apart from routine urine testing, further evaluation is required to better characterise the nature of voiding dysfunction. These often include uroflowmetry, postvoid residual (PVR), ultrasound (USG), urodynamic study and cystoscopy, depending on varying indications.[2] Overall clinical and investigational profile provides the best opportunity to assess the nature of disease. However, the
\end{abstract}

Financial or Other, Competing Interest: None.

Submission 08-07-2017, Peer Review 01-08-2017,

Acceptance 07-08-2017, Published 14-08-2017.

Corresponding Author:

Dr Ranjan Kumar Dey,

10 Gurusaday Rd, Ajanta Apartments,

Flat 8B, Kolkata-700019.

E-mail: ranjankdey@rediffmail.com

DOI: $10.14260 /$ jemds/2017/1014 difficulty arises in diagnosing the BOO confidently, due to lack of standardisation of these studies.

Urodynamic parameters in women alter significantly from men, due to different nature of voiding pattern. Women void with rather lower detrusor pressure, but higher flow rate.[3] Various nomograms based on Qmax and PdetQmax or PdetQmax have been developed in the past to quantify the B00. However, studies differ in their pressure flow combinations to define BOO, varying from Qmax lower than $10-15 \mathrm{~mL} / \mathrm{s}$ and PdetQmax $>20-30 \mathrm{~cm} \mathrm{H}_{2} \mathrm{O} .{ }^{[4]}$ Similarly, no true cut-off level of PVR and maximum voided volume (MVV) has been proposed.

In the present study, we compared the different urodynamic parameters including PVR and MVV in women presenting with obstructive urinary symptoms to the patients of renal calculus disease with normal voiding, in an attempt to find a threshold pressure flow values to define BOO precisely.

\section{MATERIALS AND METHODS}

A total of 80 female patients with bothersome lower urinary tract symptoms (LUTS) presenting to the Department of 
Urology were included during the study period from March 2014 to December 2016. 20 patients admitted for renal calculus disease with no voiding complaints along with sterile urine were taken as control. Prospective observational study was approved by the institutional ethical committee. Patients with age $<14$ years, neurological disorder, UTI, malignancy and stone diseases were excluded. Study patients were divided into three groups on symptom basis. Patients with predominantly obstructive symptoms such as poor flow, intermittency, hesitancy, prolonged voiding and straining were kept in group A, while group B had the patients with predominant irritative symptoms such as frequency, urgency and nocturia. Group C acted as control.

All patients underwent clinical evaluation including history and physical examination, urine culture, non-invasive uroflowmetry and PVR measurement by Ultrasound. Last two parameters were checked twice to ensure the consistency, with a preferable interval of 2-3 hours in the same sitting. Minimum voided volume of $150 \mathrm{~mL}$ was considered before interpreting uroflowmetry. A written informed consent was taken prior to the evaluation. Multi-channel urodynamic study was performed using transurethral $6 \mathrm{~F}$ infant feeding tube and rectal balloon catheter, with a medium infusion rate of $20-30 \mathrm{~mL} / \mathrm{min}$. VCUG was not done. Urethra was assessed via 19 "Fr urethroscope and findings were noted as either normal or stenosed. Stenosis was conferred as the area of narrowing visible in the urethra or gripping felt during urethroscopy. A higher value of Qmax from non-intubated uroflowmetry and lower value of PVR were taken for the analysis from 2 consecutive readings.

Descriptive analysis of Qmax, PVR, PdetQmax, MVV, DO and BOOI were obtained. ANOVA with post-hoc comparison and Chi-square test were used to check correlation of different parameters in between groups. Outcome in terms of presence or absence of obstruction was measured on the basis of combination of findings of clinical examinations, uroflowmetry, PVR and cystourethroscopy. Receiver operating characteristic (ROC) curve along with area under curve (AUC) and significance level were measured for Qmax, PVR, PdetQmax and BOOI to determine best set of values with higher sensitivity and specificity to define obstruction.

Two fixed set of pressure flow combinations were also tested to assess the obstruction accurately. Set 1 used Qmax $<12 \mathrm{~mL} / \mathrm{s}$ with PdetQmax $>20 \mathrm{~cm} \mathrm{H}_{2} \mathrm{O}$ and set 2 utilised Qmax $<15 \mathrm{~mL} / \mathrm{s}$ and PdetQmax $>30 \mathrm{~cm} \mathrm{H}_{2} \mathrm{O}$. Their respective sensitivity, specificity and predictive values were calculated using crosstab chart and kappa value. Confidence interval was set at $95 \%$ and $\mathrm{P}$ value $<0.05$ was taken as significant. SPSS software version 16 was used for statistical analysis.

\section{RESULTS}

A total of 100 patients were studied, including 20 as control. Group A (obstructive LUTS) had 27 participants, while group B (irritative LUTS) and C (control) consisted of 53 and 20 participants respectively. Mean age was $43 \pm 17$ (years) in group $A, 40 \pm 14$ in group $B$ and $37 \pm 12$ in group C. Urodynamic parameters including PVR between groups have been presented in table 1 . One way ANOVA showed significant differences among groups in $\operatorname{Qmax}[\mathrm{F}(2,97)=$ $38.58, \mathrm{p}=0.0005$, eta squared $=0.443]$ and PVR $[\mathrm{F}(2,97)=$ $14.8, \mathrm{p}=0.0005$, eta squared $=0.23$ ]. Post-hoc analysis using Dunnett T3 test further revealed lower Qmax in group A compared to group $\mathrm{B}$ and control both $\left[\mathrm{MD}_{\mathrm{A}-\mathrm{B}}=-5.94, \mathrm{p}=\right.$ $0.0005,95 \% \mathrm{CI}=-9.6$ to $-2.3 \& \mathrm{MD}_{\mathrm{A}-\mathrm{C}}=-15.5, \mathrm{p}=0.0005,95 \%$ $\mathrm{CI}=-18.7$ to -12.2$]$ and higher PVR in group A than in other groups $\left[\mathrm{MD}_{\mathrm{A}-\mathrm{B}}=120, \mathrm{p}=0.005,95 \% \mathrm{CI}=30\right.$ to $209 \& \mathrm{MD}_{\mathrm{A}-\mathrm{C}}=$ $187, \mathrm{p}=0.0005,95 \% \mathrm{CI}=105$ to 268] (Figure $1 \mathrm{a} \& \mathrm{~b}$ ).

Overall difference in PdetQmax $[\mathrm{F}(2,97)=2.8, \mathrm{p}=.061$, eta squared $=.05]$ and $\operatorname{MVV}[\mathrm{F}(2,97)=1.3, \mathrm{p}=.26$, eta squared $=0.02]$ among groups was not found significant, however subgroup analysis using Dunnett T3 test showed higher PdetQmax in group $\mathrm{A}$ and $\mathrm{B}$, compared to control $\left[\mathrm{MD}_{\mathrm{A}-\mathrm{c}}=9.6, \mathrm{p}=0.001,95 \% \mathrm{CI}=3.7\right.$ to $15.4 \& \mathrm{MD}_{\mathrm{B}-\mathrm{C}}=7.5, \mathrm{p}=$ $0.01,95 \% \mathrm{CI}=1.4$ to 13.5 ] (Figure $1 \mathrm{c}$ ). Urethral stenosis was found in $8 / 27$ patients in group A (29\%), in 4/53 patients in group B $(7.5 \%)$ and none in control group (Pearson ChiSquare value $=11.67, \mathrm{df}=2, \mathrm{p}=0.003$ ). Uterine prolapse was noted in 4 cases of group A and 2 of group B. Cystoscopy showed obstructive changes of different grades in $17 / 27$ of group A (63\%), 14/53 cases in group B (26.3\%) and none in control group [Pearson Chi-Square value $=23.52, \mathrm{df}=6$, $\mathrm{p}=0.001]$.

Based on combination of clinical, urodynamic, cystoscopic and imaging finding, bladder outlet obstruction (BOO) was found in 16/27 patients in group A (59.3\%), 9/53 in group B $(17 \%)$ and none in group $C$ [Pearson Chi-Square value = 25.38, $\mathrm{df}=2, \mathrm{p}=0.0005]$. Urodynamic parameters in obstructed and non-obstructed group are presented in table 2. Urethral stenosis was noted in $36 \%$ (9/25) of women with B00. ROC curve analysis for defining BOO based on BOOI, Qmax, PdetQmax, PVR and MVV revealed area under curve (AUC) of $0.956,0.939,0.866,0.810$ and 0.809 , respectively (Figure 2). Best predictive cut-off values of different parameters were predicted while balancing for higher sensitivity and specificity in defining BOO [Table 3]. A fixed pressure flow combination of set 1 had Kappa value of 0.762 , while set 2 had value of 0.690 .

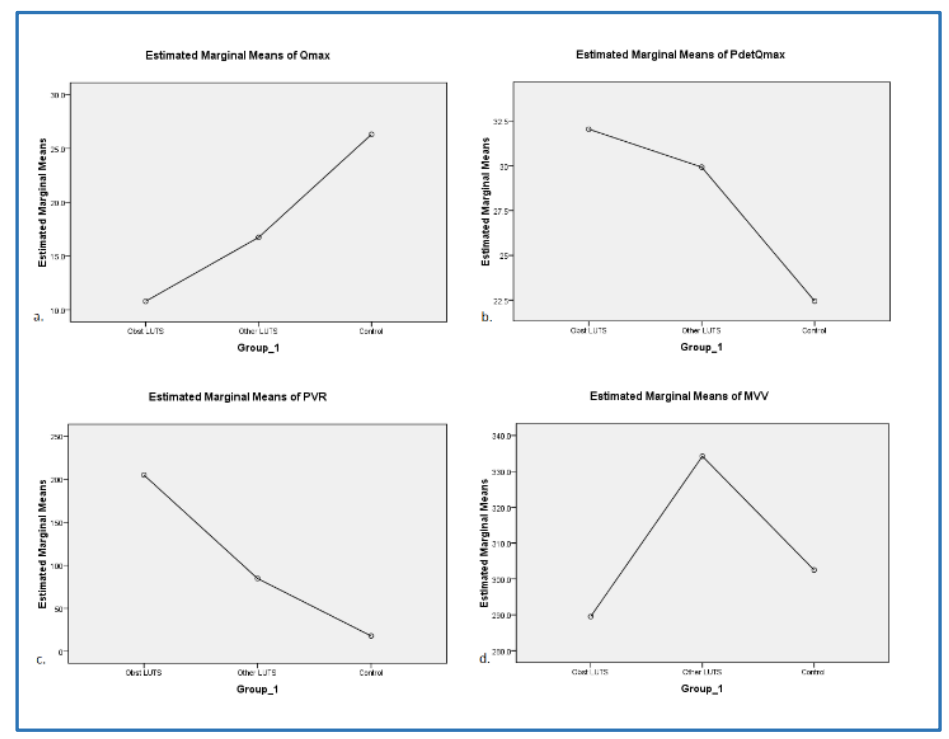

Figure 1. Graph Showing Estimated Marginal means of Qmax (a), PdetQmax (b), PVR (c) and MVV (d) In Study and Control Groups. 


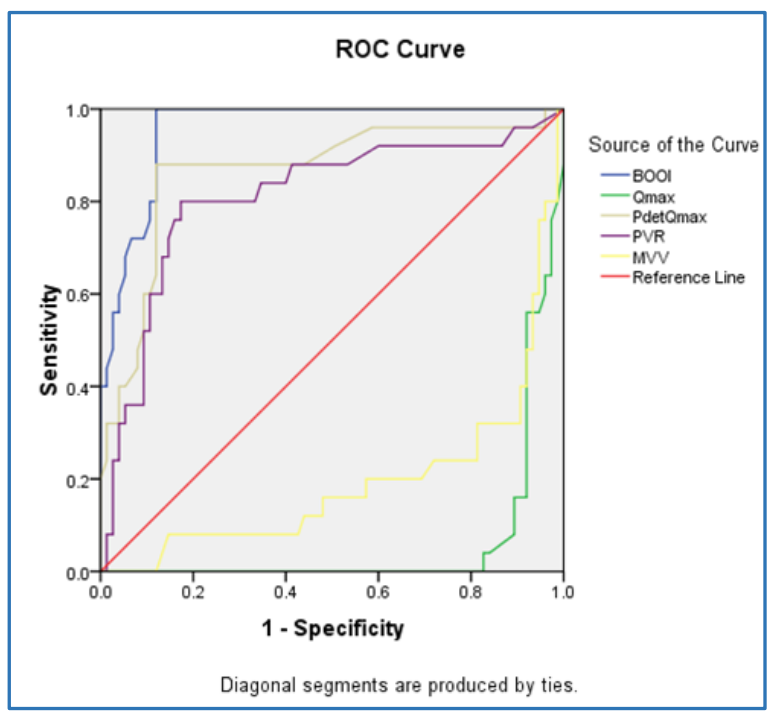

Figure 2. ROC Curve for Determining BOO based on BOOI, Qmax, PdetQmax, PVR and MVV.

\begin{tabular}{|c|c|c|c|c|c|}
\hline \multicolumn{2}{|c|}{ Group } & Qmax (mL/s) & PdetQmax (cm H2O) & PVR (mL) & MVV (mL) \\
\hline Group A (Obst LUTS) N = 27 & M \pm SD & $10.79 \pm 5.89$ & $32.04 \pm 11.67$ & $204 \pm 166$ & $289 \pm 162$ \\
\hline Group B (Irritative LUTS) N = 53 & M \pm SD & $16.74 \pm 6.85$ & $29.92 \pm 17.43$ & $84 \pm 118$ & $334 \pm 117$ \\
\hline Group C (Control) N = 20 & M \pm SD & $26.31 \pm 2.83$ & $22.45 \pm 2.52$ & $17.9 \pm 9.7$ & $302 \pm 45$ \\
\hline
\end{tabular}

\begin{tabular}{|c|c|c|c|c|c|c|}
\hline \multicolumn{2}{|c|}{ Group } & $\begin{array}{c}\text { Obstructed cases } \\
(\mathbf{N}=\mathbf{2 5})\end{array}$ & Non-Obstructed cases (N = 55) & Control (N = 20) & P value & $\begin{array}{c}\text { Partial } \\
\text { Eta Squared }\end{array}$ \\
\hline $\mathrm{Qmax}(\mathrm{mL} / \mathrm{s})$ & $\mathrm{M} \pm \mathrm{SD}$ & $8.15 \pm 3.68$ & $17.72 \pm 6.19$ & $26.31 \pm 2.82$ & 0.0005 & .593 \\
\hline Pdet $\mathrm{Qmax}\left(\mathrm{cm} \mathrm{H} \mathrm{H}_{2} \mathrm{O}\right)$ & $\mathrm{M} \pm \mathrm{SD}$ & $43.36 \pm 20.54$ & $24.85 \pm 7.94$ & $22.45 \pm 2.52$ & 0.0005 & .338 \\
\hline $\mathrm{PVR}(\mathrm{mL})$ & $\mathrm{M} \pm \mathrm{SD}$ & $203 \pm 160$ & $89.8 \pm 126.6$ & $17.9 \pm 9.75$ & 0.0005 & .214 \\
\hline $\mathrm{MVV}(\mathrm{mL})$ & $\mathrm{M} \pm \mathrm{SD}$ & $213 \pm 109$ & $367.1 \pm 117.5$ & $302.5 \pm 45.39$ & 0.0005 & .277 \\
\hline \multicolumn{7}{|c|}{ Table 2. Urodynamic Parameters in Obstructed, Non-obstructed and Control Groups } \\
\hline
\end{tabular}

\begin{tabular}{|c|c|c|c|c|c|c|c|}
\hline \multirow{2}{*}{$\begin{array}{l}\text { Test Result } \\
\text { Variable(s) }\end{array}$} & \multirow{2}{*}{ Area } & \multirow{2}{*}{$\begin{array}{l}\text { Asymptotic } \\
\text { Sig.b }\end{array}$} & \multicolumn{2}{|c|}{ Asymptotic 95\% Confidence Interval } & \multirow{2}{*}{$\begin{array}{c}\text { Predictive } \\
\text { cut-off value }\end{array}$} & \multirow{2}{*}{ Sensitivity } & \multirow{2}{*}{ Specificity } \\
\hline & & & Lower Bound & Upper Bound & & & \\
\hline BOOI & 0.956 & 0.000 & 0.921 & 0.991 & 4.7 & $100 \%$ & $88 \%$ \\
\hline Qmax & 0.939 & 0.000 & 0.894 & 0.984 & 13.15 & $89.3 \%$ & $88.0 \%$ \\
\hline PdetQmax & 0.866 & 0.000 & 0.773 & 0.959 & 28.50 & $88.0 \%$ & $86.7 \%$ \\
\hline PVR & 0.810 & 0.000 & 0.700 & 0.919 & 68.5 & $80.0 \%$ & $80.0 \%$ \\
\hline MVV & 0.809 & 0.000 & 0.701 & 0.917 & 290.5 & $80.0 \%$ & $76.0 \%$ \\
\hline
\end{tabular}

a- Under non parametric assumption.

b- Null hypothesis: true area $=0.5$.

\begin{tabular}{|c|c|c|c|c|c|}
\hline Authors & $\begin{array}{c}\text { Cases/ } \\
\text { Control (N) }\end{array}$ & $\mathrm{Qmax}(\mathrm{mL} / \mathrm{s})$ & $\begin{array}{l}\text { PdetQmax } \\
\left(\mathrm{cm} \mathrm{H}_{2} \mathrm{O}\right)\end{array}$ & PVR (mL) & Other \\
\hline Farrar et al. [1976] & 162 & $<15$ & $>50$ & $>=200$ & \\
\hline Diokno AC [1984] & 3 & $<15$ & $>60$ & & Radiographic e/o BOO \\
\hline Massey and Abrams [1988] & 163 & $<12$ & $>50$ & Significant & urethral resistance $>0.2$ \\
\hline Bass and Leach [1991] & & $<15$ & & $>100$ & Shape of the pressure-flow curve \\
\hline Chassagne et al. [1998] & $35 / 124$ & $>=15$ & $>20$ & - & - \\
\hline Nitti et al. [1999] & 261 & $<15$ & $>20$ & & Radiographic e/o BOO \\
\hline Blaivas and Groutz [2000] & 600 & $<12$ & $>20$ & & Radiographic e/o BOO \\
\hline Lemack GE [2000] & $87 / 124^{*}$ & $=<11$ & $>=21$ & & \\
\hline Defreitas GA, et al. [2004] & $80 / 20$ & $<12$ & $>=25$ & & \\
\hline Kuo HC [2004] & $70 / 265 * / 30$ & $=<15$ & $>=35$ & & PdetQmax >=30 for screening \\
\hline Di Grazia E, et al. [2004] & $43 / 136$ & $=<13$ & $>=22$ & 96 & \\
\hline Gravina GL [2007] & $133 / 37$ & $=<15$ & $>=28$ & & BOOI >= -8 \\
\hline Mostafa M et al. [2013] & $60 / 27^{*}$ & $<15$ & $>30$ & $>100$ & $\mathrm{MVV}<170 \mathrm{ml}$ \\
\hline Our Series [2016] & $80 / 20$ & $<13.15$ & $>=28.5$ & $>68.5$ & BOOI $>4.7$ \\
\hline
\end{tabular}

*Patient with SUI taken as control. 


\section{DISCUSSION}

Bladder outlet obstruction in females still remains a topic of curiosity, despite recent widespread research in the area. Much has been said, but general consensus on various aspects needs further discussion. Incidence has been varied, ranging from $2.7-23 \%$, due to non-uniform definitions.[5] In our study, it measured $31.25 \%(25 / 80)$. Symptoms alone are insufficient in predicting BOO. Hubeaux et al found no correlation between obstructive symptoms and BOO, however, they defined BOO solely on the basis of uroflowmetry $<15 \mathrm{~mL} / \mathrm{s}$ and PVR $>50 \mathrm{~mL}$.[6] Similarly, Rivas et al showed no definite determination between SUI, UUI and BOO by AUA symptom index, but good quantification of voiding symptom.[7] However, Groutz et al reported a higher AUA symptom index score in BOO patients compared to SUI group and control (15.8 \pm 8.4 versus $10.3 \pm 6.4$ and $2.1 \pm 2.7) \cdot[8]$

We found significant higher percentage of BOO in patients with predominant obstructive symptoms compared to other LUTS (59.3\% v/s 17\%, P = 0.0005). A significant low Qmax and high PVR were also reported in the obstructive LUTS patients, but PdetQmax and MVV didn't differ much in different symptom groups. We found good prediction capability of B0OI, Qmax and PdetQmax in defining B00, based on AUC analysis and moderate capability of PVR and MVV [Table 3]. Though originally described for men, few authors found BOOI a useful marker in women also. Gravina et al suggested BOOI cut-off $>$ or $=-8$ with sensitivity of $80.8 \%$ and specificity of $86.1 \%$ for female BO0.[9] We found a BOOI cut-off of 4.7 provided $100 \%$ sensitivity and $88 \%$ specificity. In terms of Qmax and PdetQmax, different set points have been proposed by various authors, ranging from 12 to 15 $\mathrm{mL} / \mathrm{s}$ and 20 to $30 \mathrm{~cm} \mathrm{H}_{2} \mathrm{O}$ respectively (Table 4).[10-19] Our data showed Qmax $<13.15 \mathrm{~mL} / \mathrm{s}$ predicted $\mathrm{BOO}$ with $89.3 \%$ sensitivity and $88 \%$ specificity, while PdetQmax $>=28.5 \mathrm{~cm}$ $\mathrm{H}_{2} \mathrm{O}$ had $88 \%$ sensitivity and $86.7 \%$ specificity. PVR $>=68.5$ $\mathrm{mL}$ also showed moderate correlation with BOO.

A fixed pressure flow combination of set 1 ( $Q$ max $<12$ $\mathrm{mL} / \mathrm{s}$, PdetQmax $>20 \mathrm{~cm} \mathrm{H}_{2} \mathrm{O}$ ) showed good agreement in identifying BOO accurately [Kappa value $=0.762$ ] with sensitivity of $80 \%(20 / 25)$ and specificity of $94.5 \%(52 / 55)$. Set $2\left(\mathrm{Qmax}<15 \mathrm{~mL} / \mathrm{s}\right.$, PdetQmax $\left.>30 \mathrm{~cm} \mathrm{H}_{2} \mathrm{O}\right)$ had moderate to good agreement [Kappa value $=0.690$ ] with a bit higher sensitivity of $84 \%(21 / 25)$, but lower specificity of $87.3 \%$ (48/55). Significance of bladder trabeculations (BT) in females is not entirely clear, unlike men. Gowda et al in his study of 551 women undergoing cystoscopy found association of BT with higher degree of prolapse, increased DO and UUI.[20] We found a good correlation of increasing grade of BT with low Qmax, high PdetQmax and high PVR $[\mathrm{p}=0.001$ (Partial Eta Sq $=0.388$ ), $\mathrm{p}=0.001$ (Partial Eta $S q=0.29), p=0.001$ (Partial Eta $S q=0.17$ ) respectively].

Various aetiologies for BOO have been described, most common being anti-incontinence surgery nowadays, followed by dysfunctional voiding (DV), urethral stenosis (US), pelvic organ prolapse (POP), urethral diverticulum, cyst, carbuncle, carcinoma and pelvic tumours.[21] In our series, US $(9 / 25)$ and POP (5/25) were more common than DV (4), postsurgery (3), post-RT (3) and carbuncle (1). Cystoscopy is good tool, not only for assessing site of obstruction, urethral dispensability, also the bladder wall changes.[22] We found it particularly helpful in grading of UB obstructive changes, discovered in 22 out of 25 (88\%) cases of BOO (Grade 1 in $28 \%$, grade 2 in $52 \%$ and grade 3 in $8 \%$ ). So, various studies have given great insight into the female voiding patterns and a cumulative data from these might help to bring uniformity to better characterise B00. Limitations of this study may be the non-utilisation of VUDS, which has shown promising results recently. Control population consisting more of younger cases might also bring out subtle differences in comparison. Repeat UDS have shown some benefit in unequivocal cases, not considered in our series.[23]

\section{Limitation}

Less Number of Controls Compared to Study population.

\section{CONCLUSION}

Urodynamic study considerably helps in evaluating obstructive voiding symptoms in females. Our data finds Qmax $<13.1 \mathrm{~mL} / \mathrm{s}$, PdetQmax $>=28.5 \mathrm{~cm} \mathrm{H}_{2} \mathrm{O}$, BOOI of $>=4.7$ and PVR of $>=68.5 \mathrm{~mL}$, as a cut-off limit to define BOO. Cystoscopy adds useful information regarding bladder outlet and bladder wall changes. A fixed pressure flow combinations give variable results, with lower set of values increasing the sensitivity, but at the cost of specificity and vice versa.

\section{ACKNOWLEDGEMENT}

Dr. Aseem Kumar Dey, for assisting in conducting urodynamics.

\section{REFERENCES}

[1] Yande S, Joshi M. Bladder outlet obstruction in women. Journal of Mid-Life Health 2011;2(1):11-7.

[2] Raheem AA, Madersbacher H. Voiding dysfunction in women: how to manage it correctly. Arab Journal of Urology 2013;11(4):319-30.

[3] Groutz A, Blaivas JG, Chaikin DC. Bladder outlet obstruction in women: definition and characteristics. Neurourol Urodyn 2000;19(3):213-20.

[4] Lemack GE. Urodynamic assessment of bladder-outlet obstruction in women. Nat Clin Pract Urol 2006;3(1):38-44.

[5] Elmissiry MM, Ali AG, Ali GA. Different urodynamic patterns in female bladder outlet obstruction: can urodynamics alone reach the diagnosis? Arab Journal of Urology 2013;11(2):127-30.

[6] Hubeaux K, Deffieux X, Jousse M, et al. Correlation between voiding dysfunction symptoms and uroflowmetry in women suffering from stress urinary incontinence. Indian Journal of Urology 2012;28(3):313-7.

[7] Groutz A, Blaivas JG, Fait G, et al. The significance of the American urological association symptom index score in the evaluation of women with bladder outlet obstruction. J Urol 2000;163(1):207-11.

[8] Rivas DA, Chancellor MB. Utility of the American urological association symptom index in the diagnosis of women with voiding dysfunction. Int Urogynecol J 1994;5(4):202-7.

[9] Gravina GL, Costa AM, Ronchi P, et al. Bladder outlet obstruction index and maximal flow rate during urodynamic study as powerful predictors for the detection of urodynamic obstruction in women. Neurourol Urodyn 2007;26(2):247-53. 
[10] Farrar DJ, Osborn JL, Stephenson TP, et al. A urodynamic view of bladder outflow obstruction in the female: factors influencing the results of treatment. $\mathrm{Br}$ J Urol 1976;47(7):815-22.

[11] Diokno AC, Hollander JB, Bennett CJ. Bladder neck obstruction in women: a real entity. J Urol 1984;132(2):294-8.

[12] Massey JA, Abrams PH. Obstructed voiding in the female. Br J Urol 1988;61(1):36-9.

[13] Bass JS, Leach GE. Surgical treatment of concomitant urethral diverticulum and stress incontinence. Urol Clin North Am 1991;18(2):365-73.

[14] Chassagne S, Bernier PA, Haab F, et al. Proposed cutoff values to define bladder outlet obstruction in women. Urology 1998;51(3):408-11.

[15] Nitti VW, Tu LM, Gitlin J. Diagnosing bladder outlet obstruction in women. J Urol 1999;161(5):1535-40.

[16] Lemack GE, Zimmern PE. Pressure flow analysis may aid in identifying women with outflow obstruction. J Urol 2000;163(6):1823-8.

[17] Defreitas GA, Zimmern PE, Lemack GE, et al. Refining diagnosis of anatomic female bladder outlet obstruction: comparison of pressure-flow study parameters in clinically obstructed women with those of normal controls. Urology 2004;64(4):675-9.
[18] Kuo HC. Urodynamic parameters for the diagnosis of bladder outlet obstruction in women. Urol Int 2004;72(1):46-51.

[19] Di Grazia E, Sanromán TR, Aceves JG. Proposed urodynamic pressure-flow nomogram to diagnose female bladder outlet obstruction. Arch Ital Urol Androl 2004;76(2):59-65.

[20] Gowda M, Danford JM, Hu Y, et al. Clinical findings associated with bladder trabeculations in women. Int Urogynecol J 2013;24(7):1167-71.

[21] McCrery RJ, Appell RA. Bladder outlet obstruction in women: iatrogenic, anatomic, and neurogenic. Curr Urol Rep 2006;7(5):363-9.

[22] Dmochowski RR. Bladder outlet obstruction: etiology and evaluation. Reviews in Urology 2005;7(Suppl 6):S3-13.

[23] Bellucci CH, Wöllner J, Gregorini F, et al. Neurogenic lower urinary tract dysfunction--do we need same session repeat urodynamic investigations? J Urol 2012;187(4):1318-23. 